ISSN 2447-9071

doi https://doi.org/10.36414/rbmc.v6i16.58

Contato para correspondência:

Leonardo Luiz Borges

E-mail:

leonardo.cbb@pucgoias.edu.br

Conflito de interesse: Não

Financiamento: Recursos próprios

Recebido: $12 / 10 / 2020$

Aprovado: 07/11/2020

\title{
Investigação in silico de compostos bioativos de Croton linearifolius Müll.Arg com atividade antidepressiva
}

\section{In silico investigation of bioactive compounds of Croton linearifolius Müll.Arg with antidepressant activity}

\author{
Gabriel Guimarães Tavares', Suzana Ferreira Alves ${ }^{1,2}$, Leonardo Luiz Borges ${ }^{1,3}$ \\ 'Pontifícia Universidade Católica de Goiás - PUC Goiás \\ ${ }^{2}$ Faculdades Objetivo - IUESO \\ ${ }^{3}$ Universidade Estadual de Goiás - UEG
}

\begin{abstract}
Resumo
A depressão está entre as maiores causas de incapacidade em todo o mundo. Portanto, a busca de inovações terapêuticas énecessária e, neste contexto, os estudos in silico constituem uma ferramenta fundamental para o desenvolvimento de novos medicamentos de maneira mais rápida e ampla. No presente trabalho investigou-se moléculas selecionadas nas bases de dados PubMed, ScienceDirecte SCiELO. Os servidores PASS online e SwissADME foram usados para análise de biodisponibilidade oral e Pred-HERG e ToxTree para prever toxicidades cardíacas e sistêmicas. As atividades biológicas foram analisadas no PASS online e os alvos moleculares no SwissTargetPrediction. Em acréscimo foram realizadas, foram realizadas análises farmacofóricas e acoplamento molecular. Para corroboraromodelo empregado no acoplamento molecular, foi realizado um redocking. Dentre as moléculas avaliadaso a-pineno, derivado de monoterpenos naturais, pode ser encontrado na região sul brasileira, extraído de Croton linearifolius Müll.Arg. A atividade biológica no PASS onlinee SwissADME mostra efeitos corroboradores como antidepressivo. A verificação desse efeito foianalisadaporacoplamento do a-pineno com a estrutura cristalográfica transportador de serotonina (SERT) que foi selecionado do (PDB ID: 5/6X). A análise de redocking feita com o complexo do transportador com a paroxetina estabeleceu os parâmetros do modelo de interação. O a-pineno é competidor pelo receptor do transportador de serotonina promissor, demonstrado pelo modelo farmacofórico e pela análise de acoplamento molecular. Esse estudo contribui como fundamento de perspectiva dessa molécula como um futuro fármaco antidepressivo.
\end{abstract}

Palavras-Chave: Plantas medicinais, a-pineno, Ferramentas in silico, Antidepressivos. 
promising serotonin transporterreceptor, demonstrated by the pharmacophoricmodel and molecular coupling analysis. This analysis helps to clarify its use as a possible antidepressant.

Keywords: Medicinal plants, a-pinene, In silico study, Antidepressant.

\section{Introdução}

A depressão segundo a Organização Mundial da Saúde (OMS) é um transtorno mental caracterizado por tristeza persistente e pela perda de interesse em atividades que normalmente são prazerosas, acompanhadas da incapacidade de realizar atividades diárias, durante pelo menos duas semanas, as causas possíveis incluem uma combinação de origens biológicas, psicológicas e sociais de angústia e esses fatores podem causar mudanças na função cerebral, incluindo alteração na atividade de determinados circuitos neuronais no cérebro'. A depressão pode ser classificada como leve, moderada ou grave, a depender da intensidade dos sintomas.

De forma que o indivíduo com um episódio depressivo leve, terá que se esforçar para continuar um trabalho simples e também afetará atividades sociais, mas sem grande dano ao funcionamento geral. Já durante um episódio depressivo grave, é improvável que a pessoa afetada possa continuar com as atividades cotidianas, seja no trabalho, domésticas ou sociais. Existe uma distinção que é feita entre depressão em pessoas que já tiveram ou não um histórico que envolvesse episódios de mania. Ambos os tipos tendem a ser crônicos, com recaídas, especialmente se não forem tratados².

Segundo a OMS, a depressão atualmente representa 4,3\% da carga global de doenças e está entre as maiores causas de incapacidade em todo o mundo, $11 \%$ de pessoas de todas as idades vivem com incapacidade, envolvendo principalmente mulheres. As consequências econômicas dessas perdas de saúde são igualmente grandes, um estudo recente estimou que o impacto global acumulado dos transtornos mentais em termos de produção econômica perdida será de US $\$ 16,3$ milhões entre 2011 e 2030. Mesmo com esses números, entre $76 \%$ e $85 \%$ das pessoas com transtornos mentais graves não recebem tratamento nos países de baixa e média renda; a faixa correspondente para os países de alta renda também é alta: entre $35 \%$ e $50 \%$. Os gastos anuais em saúde mental são inferiores a US $\$ 2$ por pessoa e inferiores a US $\$ 0,25$ por pessoa em baixa renda países, com $67 \%$ desses recursos financeiros alocados em hospitais psiquiátricos independentes ${ }^{3}$.

A serotonina representada na Figura 1 é um neurotransmissor e regulador bioquímico, sintetizado a partir do aminoácido essencial L-triptofano, atua como um transmissor local nas sinapses e como um modulador parácrino ou hormonal dos circuitos após a difusão, permitindo uma ampla variedade de respostas comportamentais a diferentes estímulos. Alguns dos efeitos da serotonina incluem a modulação do sono, o estado de excitação e o comportamento sexual, e as deficiências do sistema serotonérgico causam distúrbios como depressão, transtorno obsessivo-compulsivo, fobias, estresse pós-traumático distúrbio, epilepsia e transtorno de ansiedade generalizada. A serotonina possui três modos diferentes de ação no sistema nervoso: como transmissor, agindo localmente nos botões sinápticos; mediante a difusão a distância de seus locais de liberação produz efeitos parácrinos e circulando na corrente sanguínea, produzindo efeitos hormonais. Os três modos podem afetar um único circuito neuronal ${ }^{4}$.

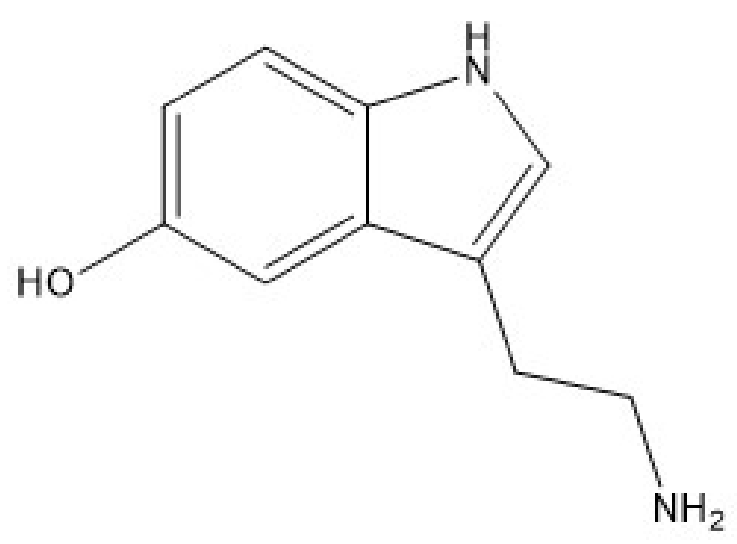

Figura 1. Estrutura 2D da serotonina.

Para a investigação de novas moléculas bioativas, estudos in silico vêm se apresentando cara vez mais alvo de grande atenção por parte da indústria farmacêutica na predição de propriedades de absorção, distribuição, metabolismo, excreção (ADME), toxicidade e predições de alvos de moléculas que podem ter grande probabilidade de serem candidatas nas fases de desenvolvimento clínico. Existe uma gama de propriedades que é possível de ser analisadas, dentre elas a absorção oral, biodisponibilidade, penetração na barreira hematoencefálica, depuração e volume de distribuição, essas e outras propriedades do estudo in silico reduz o risco de problemas nos estágios finais, otimizando a triagem e testando moléculas de maneira mais clara e objetiva ${ }^{5}$. 
Plantas medicinais, são uma fonte interessante para a investigação in silico, por apresentar inúmeros metabólitos provenientes da biossíntese vegetal importantes para o vegetal, o que instiga a descoberta para potenciais fármacos. $\mathrm{O}$ gênero Croton em sua maioria apresenta substâncias com potencial medicinal, porém as atividades de comum uso são de inseticida, antifúngica, antimicrobiana, antioxidante, dentre outras $^{6}$. A espécie Croton linearifolius Müll.Arg. está distribuída na região sul do Brasil, mais precisamente no Paraná e Santa Catarina, é conhecida popularmente como velame pimenta e mais usada popularmente como inseticida, porém em sua constituição há uma grande concentração de monoterpenos ${ }^{7}$.

Devido ao aumento dos da incidência da depressão no Brasil e no mundo, esse trabalho tem como objetivo a busca por meio de técnicas in silico de novas moléculas com potencial antidepressivo a partir da espécie Croton linearifolius Müll.Arg.

\section{Métodos}

Triagem de compostos presentes em Croton linearifolius Müll.Arg

As moléculas investigadas neste artigo foram selecionadas em bases de dados como PubMed, ScienceDirect, Google Acadêmico e Scientific Electronic Library Online (SciELO) de espécies de plantas medicinais com potencial, dentre as plantas pesquisadas foi seleciona a espécie Croton linearifolius Müll. Arg. por apresentar grande quantidade de substâncias dentre as de sua espécie. Nove compostos monoterpenos (Tabela 1), dispostos no óleo essencial foi encontrado no mesmo gênero, foram selecionados para avaliação in silico ${ }^{7}$.

Tabela 1. Compostos identificados a partir do óleo essencial da espécie Croton linearifolius Müll.Arg para avaliação in silico.

\begin{tabular}{ccc} 
& \multicolumn{3}{c}{ Ocorrências } \\
Substâncias & Folha & Caule \\
- -Tujeno & $\mathrm{x}$ & \\
a-Pineno & $\mathrm{x}$ & $\mathrm{x}$ \\
$\beta$-Pineno & $\mathrm{x}$ & $\mathrm{x}$ \\
Mirceno & $\mathrm{x}$ & $\mathrm{x}$ \\
$\mathrm{a}$-Terpineno & $\mathrm{x}$ & $\mathrm{x}$ \\
o-Cimeno & $\mathrm{x}$ & \\
$\mathrm{y}$-Terpineno & $\mathrm{x}$ & $\mathrm{x}$ \\
$\beta$-Cimeno & $\mathrm{x}$ & \\
Terpinoleno & $\mathrm{x}$ &
\end{tabular}

Investigação farmacocinética in silico dos compostos de Croton linearifolius

A classificação druglikeness é usada para classificação e predição de alguns parâmetros farmacocinéticos das substâncias. O conceito druglikeness advém da publicação de Lipinski, (1997), que lança a 'Regra dos 5' (Ro5), amplamente difundida e usada como parâmetro na avaliação de novas moléculas quanto a seu potencial de absorção ${ }^{8}$. Essa avaliação tem como características o princípio que não poder ter mais do que 5 ligações de doadoras de hidrogênio, não mais que 10 a de ligação de hidrogênio, uma massa molecular inferior a 500 Da e LogP que seja menor que 5. As propriedades que são consideradas por Lipinski, principalmente hidrofobicidade, distribuição eletrônica, características de ligação de hidrogênio, tamanho e flexibilidade das moléculas e presença de características farmacofóricas, influem o comportamento da substância no organismo, somando a biodisponibilidade, propriedades de transporte, afinidade de proteínas, reatividade, toxicidade e estabilidade ${ }^{9}$. Foi verificado a conformidade com a regra dos cinco de Lipinski pelo servidor SwissADME (http:// www.swissadme.ch) ${ }^{10}$. A análise de predição de toxicidade foi realizada ToxTree (http://toxtree.sourceforge.net) ${ }^{11}$, que analisa toxicidade por similaridade molecular, em que prevêa toxicidade aguda, hepatotoxicidade, citotoxicidade, carcinogenicidade, mutagenicidade, imunotoxicidade.

\section{Predição das propriedades biológicas in silico}

Para predizer atividades biológicas, foi utilizado o servidor PASS (http://www.pharmaexpert.ru/passonline/)12,13 e o SwissADME. A partir da estrutura das moléculas, na forma de SMILES, foram encontrados os efeitos farmacológicos, mecanismos de ação, efeitos tóxicos e adversos, interação com enzimas e transportadores metabólicos, influência na expressão gênica e outras características.

\section{Predição de alvos moleculares}

A molécula avaliada pela plataforma SwissTargetPrediction (http://www.swisstargetprediction.ch) ${ }^{14}$ é submetida a uma trigam de alvos moleculares por meio de análises de similaridade 2D e 3D e comparando a molécula com uma biblioteca de 280.000 compostos ativos $^{13}$. Por meio de similaridade é possível analisar se a molécula tem ligação de alvo comum para determinada proteína. Pois o método do PharmMapper procura possíveis farmacóforos e relata os de maior pontuação em critério de comparação das configurações 2D e 3D com bases de dados das moléculas que já são relatadas a ligação na proteína alvo ${ }^{15-17}$. A biblioteca eletrônica utilizada para obter as proteínas alvo foram foi a do Protein Data Bank (PDB)(https:// www.rcsb.org/search) ${ }^{18}$. 


\section{Docking molecular}

Procedeu-se o docking no software GOLD Suite 5.7.0 associado à interface gráfica Hermes ${ }^{19}$. A região de interesse usada para o encaixe Gold foi definida com todos os resíduos de proteínas dentro dos $10 \AA ̊$ dos ligantes de referência que acompanharam os complexos de proteínas já existentes. $O$ valor padrão de todos os outros parâmetros foi utilizado e os complexos foram submetidos a 10 execuções de algoritmos genéticos usando a função de score ChemPLP.

\section{Resultados e Discussão}

Na pesquisa de plantas populares com uso medicinal, foi selecionada a espécie Croton linearifolius Müll.Arg. Selecionada pelo teor do a-pineno analisada ser maior dentre as da sua espécie ${ }^{20}$. O gênero Croton é um dos maiores e mais diversos da família Euphorbiaceae, sendo distribuída em sua maioria nas regiões tropicais do mundo, possuindo aproximadamente 1.200 espécies $^{7}$. No brasil, estimasse cerca de 350 espécies, tendo a maior diversidade do gênero nas regiões Sudeste e Nordeste do país ${ }^{21}$.

O gênero Croton dentre os principais compostos biologicamente ativos destacam-se os terpenoides, fenilpropanoides, flavonoides, alcaloides e tocoferóis7. O a-pineno foi selecionado dentro dos monoterpenos por ser encontrado em grande concentração e possuir os efeitos desejados, ao prever a atividade dessa substância nos servidores PASS online e SwissTargetPrediction ${ }^{13-15}$, foram encontrado efeitos antidiscinesia, antineurótico, no tratamento de distúrbios fóbicos, antagonista nicotínico do receptor alfa 6 , beta 3 , beta 4 , alfa 5 , agonismo no transportador de serotonina, no transportador de noradrenalina, no receptor muscarínico de acetilcolina M2 e no receptor canabinoide 2, que em soma corroboraram para um possível efeito antidepressivo.

A toxicidade do a-pineno quando submetida a avaliação pelo servidor Toxtree apresentou a toxicidade classe 1, sendo essa a mais baixa, não houve nenhum parâmetro violado dentro das leis de Cramer12. Quanto a toxicidade cardíaca pelo servidor Pred-hERG22,23 resultou em $60 \%$ de probabilidade de toxicidade fraca ou moderada, tendo o valor 0.19 , sendo o limite aceitável 0.26 para cardiotoxicidade, permitindo assim, concluir que o composto não é tóxico e apto ao estudo in silico.

O transportador de serotonina (SERT) que foi selecionado do site PDB (Protein Data Bank: PDB ID: 516X) é um alvo para medicamentos antidepressivos e psicoestimulantes que bloqueiam a recaptação e prolongam a sinalização de neurotransmissores. O SERT tem como função terminar a sinalização serotoninérgica por meio da recaptação dependente de sódio e cloreto do neurotransmissor nos neurônios pré-sinápticos de serotonina. A estrutura do SERT humana utilizada tem resolução de 3,15 Å e está ligada ao antidepressivo paroxetina, foi utilizado a metodologia de difração de raio-x para a categorização e elucidação do complexo ${ }^{24}$. Tendo em vista que a paroxetina é um antidepressivo consolidado como um bloqueador da recaptação de serotonina, a utilização desse complexo que comprova tal mecanismo, corrobora para analisar se a atividade do a-pineno se assemelha com o mecanismo realizado pela paroxetina.

Para corroborar a análise de ancoragem, o redocking realizado mostrou que os valores do Root Mean Square deviation (RMSD), utilizados para medir a distância entre as 3 melhores poses e a estrutura ligante co-cristalizada, foram inferiores a 1 (Figura 2). Este resultado mostra que o modelo foi adequado para predizer o perfil de encaixe entre a molécula ligante e o sítio ativo do alvo selecionado.

Para explorar as principais interações entre o a-pineno e o transportador de serotonina humana a partir da visualização das interações intermoleculares ligante-receptor, foram realizadas simulações de acoplamento molecular utilizando uma estrutura cristalina do transportador de serotonina e a estrutura do a-pineno no software GOLD (PDB ID: 5I6X) ${ }^{25}$. 0 acoplamento molecular foi realizado para ilustrar o modo de ligação do monoterpeno selecionado e o alvo. Como pode ser visto na Figura 3, o a-pineno se encaixa no sítio de ligação do receptor do transportador de serotonina, gerando 10 interações, aumentando a hipótese de que este composto possa servir como um competidor pelo receptor desse transportador, explicando seus efeitos antidepressivos, por bloquear a recaptação de serotonina ${ }^{26}$.

Como pode ser observado na Figura 4. o a-pineno apresenta ligações, Van der Walls, Alquila e $\pi$-alquila, as intenções de Van der Walls com os resíduos de glicina Gly442 e Gly338, serina Ser439 e com a valina Val343 garante e contribui para estabilizar o encaixe e estabilizar o ligante no sítio ativo do transportador de serotonina.

O a-pineno apresenta as interações com os seguintes resíduos de aminoácidos da molécula transportadora de serotonina: Ser438, lle172, Phe341, Tyr176, Asp98 e Ser439. Essas interações foram semelhantes as encontradas no estudo de Coleman, J.A. e colaboradores de 2016 sobre o complexo do transportador de serotonina e a paroxetina, o que corrobora na hipótese que o a-pineno pode apresentar uma ancoragem semelhante ${ }^{26}$. Referente as interações encontradas no docking da molécula, observamos uma apolaridade que determina um possível mecanismo de ação competitiva pelo receptor, pois as ligações de Van der Walls, Alquila e $\pi$-alquila não apresenta interações muito fortes, porém suficientes para a ancoragem. 


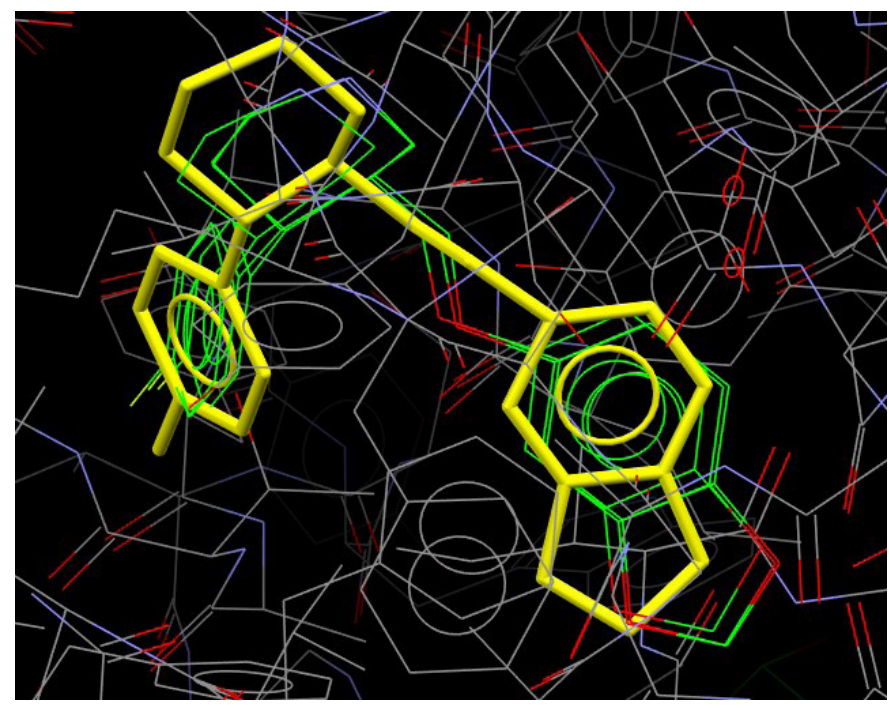

Figura 2. Melhores poses no redocking para o ligante cocristalografado (paroxetina) com alvo 516X (valores de RMSD menores que $1 \mathrm{~A}$ ).

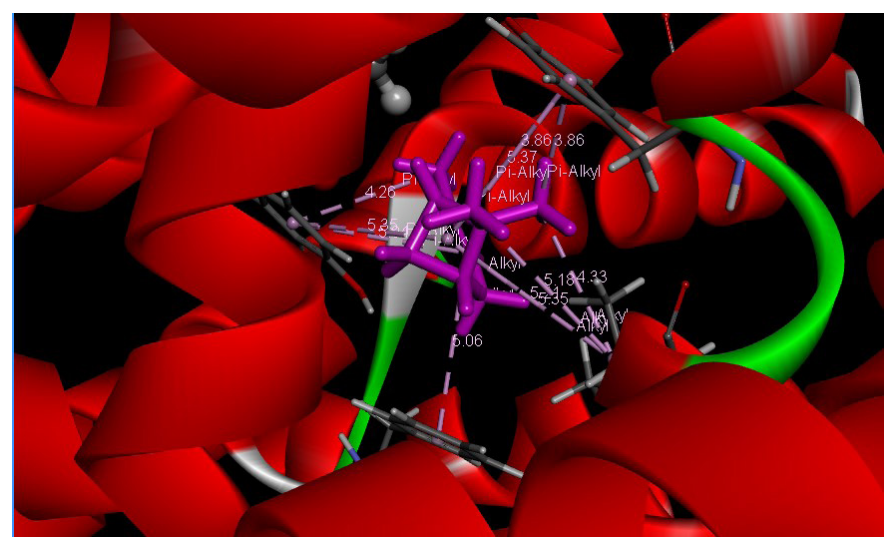

Figura 3. Pose 1 ancorada de a-pineno no local ativo do transportador de serotonina. Imagem gerada com o software Discovery Studio 3.5 Visualizer.

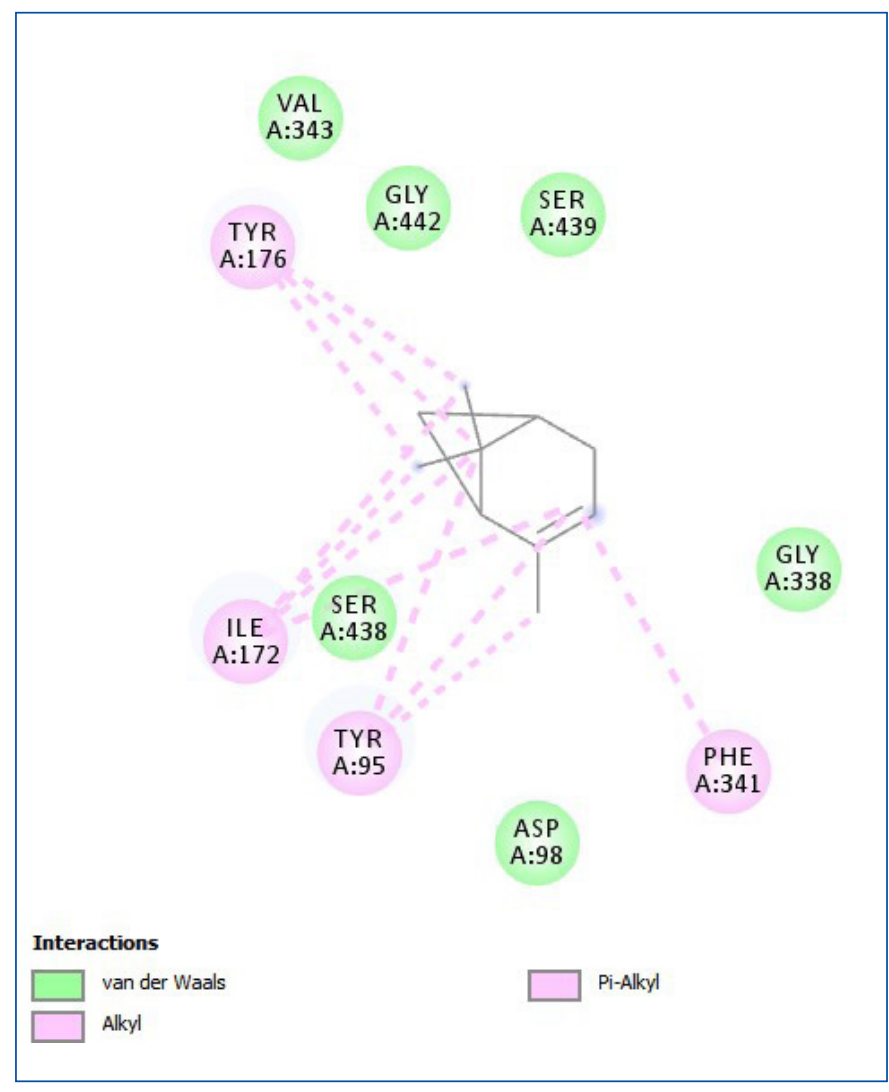

Figura 4. O diagrama de interação $2 \mathrm{D}$ do a-pineno no sítio ativo do transportador de serotonina. Imagem gerada com o Discovery Studio 3.5 Visualizer.

\section{Conclusão}

A depressão vem se mostrando cada vez mais frequente, alcançando grandes índices, englobando todas as idades, em conjunto com a frequência, cresce o interesse por novos tratamentos e dentre eles com plantas medicinais, pelos seus derivados sendo metabólitos primários e secundários. A abordagem utilizada demonstrou que o a-pineno é um monoterpeno promissor, para se ligar competitivamente com o transportador de serotonina e compartilha características químicas importantes com bloqueadores de recaptação de serotonina relatados na literatura. Esses estudos podem ajudar a elucidar efeitos relevantes dos extratos de Croton linearifolius Müll.Arg., que são ricos neste monoterpeno, para o tratamento da depressão e incentivar novos estudos com outras plantas que possui o a-pineno com relação a essa atividade. Então, o a-pineno pode ser um ponto de partida no desenvolvimento novas opções terapêuticas contra a depressão, pois apresenta pouca cardiotoxicidade e um mecanismo atípico de ação, apresentado em medicamentos já consagrados na literatura, como por exemplo na Risperidona e Olanzapina. Por fim, este artigo fornece informações para ajudar na elaboração de mais 
ensaios in vitro e in vivo com este monoterpeno e um incentivo na pesquisa de novas formas de tratamento da depressão.

\section{Referências}

1. Organização Pan-Americana da Saúde. Depressão: o que você precisa saber. 2017. Acesso em 22 de julho de 2020. Disponível em: https://www.paho.org/bra/ index.php?option $=$ com_content $\&$ view $=$ article\&id $=56$ 35:folha-informativa-depressao\&ltemid=1095https:// www.who.int/mental_health/action_plan_2013/ bw_version.pdf?ua=1.

2. Organização Pan-Americana da Saúde. Folha informativa - Depressão. acesso em 22 de julho de 2020. Disponível em: https://www.paho.org/bra/index. php?option=com_content\&view $=$ article\&id $=5635:$ fol ha-informativa-depressao\&ltemid=1095https://www. who.int/mental_health/action_plan_2013/bw_version.pdf?ua $=1$.

3. World Health Organization. Switzerland: Mental Health Action Plan 2013-2020. Acesso em 22 de julho de 2020. Disponível em: https://www.who.int/mental_health/ action_plan_2013/bw_version.pdf?ua=1.

4. National Center for Biotechnology Information. PubChem Database. Serotonin, $\mathrm{CID}=5202$, https:// pubchem.ncbi.nlm.nih.gov/compound/Serotonin (accessed on July 22, 2020).

5. Van de Waterbeemd $\mathrm{H}$, Gifford E. ADMET in silico modelling: towards prediction paradise? Nat Rev Drug Discov. 2003;2:192-204.

6. Silva VA, Oliveira CRM, Pessôa HLF, Pereira MSV. Antimicrobial efficacy of the extract of Croton sonderianus Mull. On bactéria that cause dental caries. Revista de Odontologia da UNESP. 2011;40(2):69-72.

7. Feliu DA. Análise de terpenóides de espécies de Croton sect. Lamprocroton (Mull. Arg.) Pax (Euphorbiaceae). São Paulo, 2011.

8. Walters P. Indo além da regra de Lipinski no design de medicamentos, Expert Opinion on Drug Discovery. 2012;7(2)99-107.

9. Lipinski CA, Lombardo F, Dominy BW, Feeney PJ. Abordagens experimentais e computacionais para estimar a solubilidade e permeabilidade em ambientes de descoberta e desenvolvimento de medicamentos. Adv. DrugDeliv. 2001;46(1-3):3-26.

10. SwissADME: a free web tool to evaluate pharmacokinetics, drug-likeness and medicinal chemistry friendliness of small molecules. Sci. Rep. 2017;7:42717.

11. Patlewicz G, Jeliazkova N, Safford RJ, Worth AP, Aleksiev
B. An evaluation of the implementation of the Cramer classification scheme in the Toxtree software. SAR QSAR Environ Res. 2008;19(5-6):495-524.

12. Poroikov VV, Filimonov DA, Borodina YV, Lagunin AA, Kos A. Robustness of biological activity spectra predicting by computer program PASS for noncongeneric sets of chemical compounds. J Chem Inf Comput Sci. 2000;40:1349-55.

13. Poroikov VV, Filimonov DA. How to acquire new biological activities in old compounds by computer prediction. J Comput Aided Mol Des. 2002;16:819-24.

14. SwissTargetPrediction: dados atualizados e novos recursos para previsão eficiente de alvos proteicos de moléculas pequenas, Nucl. Acids Res. 2019.

15. Liu X, Ouyang S, Yu B, Huang K, Liu Y, Gong J, et al. PharmMapper Server: um servidor da Web para identificação de possíveis alvos de medicamentos por meio do mapeamento de farmacóforo. Nucleic Acids Res. 2010;38:W609-W614.

16. Wang X, Pan C, Gong J, Liu X, Li H. Aprimorando o enriquecimento da previsão de alvos baseados em farmacóforos para os perfis polifarmacológicos de drogas. J. Chem. Inf. Modelo. 2016;56:1175-83.

17. Wang X, Shen Y, Wang S, Li S, Zhang W, Liu X, et al. Atualização PharmMapper: um servidor web para identificação de possíveis alvos de medicamentos com um banco de dados abrangente de farmacóforos. Nucleic Acids Res. 2017;45:W356-W360.

18. PDB. Pesquisa de ácidos nucléicos; 2019.

19. Cole JC, Nissink JWM, Taylor R. Protein-ligand Docking and Virtual Screening with GOLD in Virtual Screening in Drug Discovery; Shoichet, B., Alvarez, J., Eds.; Taylor \& Francis CRC Press: Boca Raton, FL, USA, 2005.

20. Berry PE, Hipp AL, Wurdack KJ, Van EEB, Riina R. Molecular phylogenetics of the giant's genus Croton and tribe Crotonae (Euphorbiaceae sensu strictu) using ITS and trnL-trn-F DNA sequence data. American Journal of Botany. 2005;9:1520-34.

21. Carneiro-Torres DS. Diversidade de Croton L. (Euphorbiaceae) no bioma Caatinga. 296 f. Tese (Doutorado em Botânica). Universidade Estadual de Feira de Santana, 2009.

22. Braga RC, Alves VM, Silva MFB, Muratov E, Fourches D, Liao L, et al. Pred-hERG: A novel web-accessible computational tool for predicting cardiac toxicity. Mol. Inform. 2015;34(10):698-701.

23. Braga RC, Alves VM, Silva MFB, Muratov E, Fourches D, Tropsha A, et al. Tuning HERG out: antitarget QSAR 
models for drug development. Top. Med. Chem. 2014;14(11):1399-415.

24. Coleman JA, Green EM, Gouaux E. X-ray structures and mechanism of the human serotonin transporter. Nature. 2016;532:334-9.

25. Lange UEW, Baucke D, Hornberger W, Mack H, Seitz W, Hoeffken HW. Orally active thrombin inhibitors. Part 2: optimization of the P2-moiety. Bioorgmedchemlett. 2006;16:2648-53.

26. Moreno RA, Moreno DH, Soares MBM. Rev. Bras. Psiquiatr. 1999;21:1.

27. Jonathan AC, Evan MG, Eric G. X-ray structures and mechanism of the human serotonin transporter. California, USA. Macmillian Publishers Limited; 2016. 